\title{
Modelos para ajuste da produção de gases em silagens de girassol e milho
}

\author{
Renius Mello(1), André Luiz Rodrigues Magalhães(2), Fernanda Cristina Breda( ${ }^{(1)}$ e Adair José Regazzi(3)
}

\begin{abstract}
(1)Universidade Federal de Roraima, Centro de Ciências Agrárias, Eagro e Departamento de Zootecnia, Avenida Capitão Ene Garcez, no 2413, Bairro Aeroporto, CEP 69304-000 Boa Vista, RR. E-mail: reniusmello@hotmail.com, fernandabreda@gmail.com (2)Universidade Federal Rural de Pernambuco, Unidade Acadêmica de Garanhuns, Avenida Bom Pastor, s/no, Bairro Boa Vista, CEP 55292-901 Garanhuns, PE. E-mail: andre30036@gmail.com (3)Universidade Federal de Viçosa, Centro de Ciências Exatas e Tecnológicas, Departamento de Informática, Avenida P.H. Rolfs, s/no, Bairro Centro, CEP 36571-000 Viçosa, MG. E-mail: adairreg@ufv.br
\end{abstract}

Resumo - O objetivo deste trabalho foi identificar entre os modelos Brody, Von Bertalanffy, Gompertz, France, Logístico, Logístico modificado e Logístico bicompartimental, aquele que apresenta maior qualidade de ajuste à curva de produção cumulativa de gases em silagens de girassol e milho. Os critérios adotados foram: coeficiente de determinação, quadrado médio do resíduo, análise gráfica das curvas observadas e estimadas, análise gráfica de dispersão dos resíduos estudentizados, erro percentual médio, eficiência relativa e número de iterações para atingir a convergência. Os modelos Brody, France e Logístico bicompartimental apresentaram os maiores valores de coeficiente de determinação em ambos os substratos, e a diferença entre eles pode ser considerada desprezível. Estes modelos apresentaram, também, os menores valores de quadrado médio do resíduo em silagens de girassol, e a diferença entre eles foi considerada desprezível. Os modelos Brody e France apresentaram menor quadrado médio do resíduo em silagens de milho. Todos os modelos apresentaram dispersão positiva dos resíduos em ambos os substratos após 144 horas de incubação. O modelo Brody apresentou menor erro percentual médio e número de iterações em ambos os substratos. Os modelos Logístico bicompartimental e France apresentaram maior eficiência relativa, respectivamente, em silagens de girassol e milho. Assim, o modelo Logístico bicompartimental apresenta maior qualidade de ajuste à curva de produção de gases em silagens de girassol e milho.

Termos para indexação: cinética, in vitro, modelo matemático, modelos não-lineares.

\section{Models for fit of gas production in sunflower and corn silages}

\begin{abstract}
The aim of this work was to identify among the Brody, Von Bertalanffy, Gompertz, France, Logistic, Modified logistic and Dual-pool logistic models, the one that presents the highest quality of fit for cumulative gas production curve in sunflower and corn silages. The quality of fit was evaluated by coefficient of determination, residual mean square, graphic analysis of the observed and estimated curves, graphic analysis of dispersion of the studentized residual, average percentage error, relative efficiency and number of iteractions to converge. Brody, France and Dual-pool logistic models showed the largest values of coefficient of determination in both substrates, and the difference among them was considered worthless. They also showed the smallest values of residual mean square in sunflower silages, being the difference among them considered worthless. Brody and France models presented smaller residual mean square in corn silages. All the models showed positive dispersion of the residual in both substrates after 144 hours of incubation. The Brody model showed smaller average percentage error and number of iterations in both substrates. The Dual-pool logistic and France models showed higher relative efficiency, respectively, in sunflower and corn silages. Thus, the Dual-pool logistic model showed higher quality of fit to the gas production curve in sunflower and corn silages.
\end{abstract}

Index terms: kinetics, in vitro, mathematical models, nonlinear models.

\section{Introdução}

As técnicas de produção de gases mais utilizadas empregam o uso de seringas de vidro graduadas (Menke et al., 1979; Menke \& Steingass, 1988), transdutor de pressão com leituras semi-automatizadas (Theodorou et al., 1994;
Maurício et al., 1999), transdutor de pressão com leituras automatizadas sem liberação dos gases (Pell \& Schofield, 1993), transdutor de pressão com leituras automatizadas e eletroválvula para liberação dos gases produzidos (Cone et al., 1996; Davies et al., 2000). Tais técnicas permitem avaliar o valor energético dos 
alimentos com a utilização de equações na estimativa da digestibilidade e cinética da degradação ruminal (Menke \& Steingass, 1988).

A descrição matemática dos perfis de produção de gases possibilita análise dos dados e comparação dos substratos ou características do ambiente de fermentação e podem fornecer informações úteis relativas à composição do substrato e fermentabilidade das frações solúveis e lentamente fermentáveis dos substratos (Groot et al., 1996). Os autores mencionaram ainda que diversos modelos nãolineares, com pressuposições e tratamentos distintos, estão disponíveis para ajuste das curvas de produção de gases na determinação dos parâmetros de degradação ou perfil de fermentação.

Entre os modelos não-lineares utilizados na descrição matemática dos perfis de produção de gases destacamse os de crescimento exponencial e sigmóide, pressupondo-se que a taxa específica de produção de gases pode ser proporcional à quantidade de substrato $\mathrm{e}$ independente da massa microbiana (exponencial com substrato limitado); independente da quantidade de substrato e proporcional à massa microbiana (exponencial simples com "cut-off"); ou proporcional à quantidade de substrato e massa microbiana (Schofield et al., 1994). Adicionalmente, os modelos podem assumir um, dois ou mais compartimentos e/ou fases de fermentação. Dessa forma, quando os resultados forem analisados por modelos diferentes, os resultados também podem ser diferentes, exigindo cautela e bom senso em sua interpretação e julgamento.

Thornley \& France (2007) descreveram vários modelos de crescimento sigmóide para sistemas biológicos, entretanto, poucos são os estudos sobre o ajuste desses modelos para a produção de gases. Segundo Beuvink \& Kogut (1993), estudos sobre modelos matemáticos com equações que descrevam satisfatoriamente a produção de gases são essenciais para adequada interpretação do valor nutritivo dos alimentos para ruminantes. Assim, a indicação de uma ou outra equação não é simples e deve envolver uma série de fatores.

O objetivo deste trabalho foi identificar entre os modelos matemáticos não-lineares aquele que apresenta maior qualidade de ajuste às curvas de produção cumulativa de gases em silagens de girassol e milho.

\section{Material e Métodos}

O experimento foi realizado no Laboratório de Nutrição Animal do Departamento de Zootecnia da
Universidade Federal de Viçosa (UFV), entre abril e dezembro de 2003.

Os substratos utilizados constituíram-se de 12 silagens de girassol (Helianthus annuus, L.) e duas silagens de milho (Zea mays, L.), obtidas da fermentação em silos laboratoriais. Os silos foram abertos 42 dias após a ensilagem. A silagem foi secada em estufa com circulação de ar forçado a $55 \pm 5^{\circ} \mathrm{C}$ até peso constante. As amostras pré-secadas foram moídas em peneira com crivos de um milímetro, utilizando-se moinho estacionário do tipo Wiley e, posteriormente, foram submetidas à técnica de produção de gases.

A técnica in vitro de produção de gases foi efetuada com algumas modificações no protocolo experimental de Pell \& Schofield (1993). Em frascos de vidro de $50 \mathrm{~mL}$ foram incubados $100 \mathrm{mg}$ das amostras, em triplicata $(\mathrm{n}=42)$, com $8 \mathrm{~mL}$ da solução tampão de McDougall (1948) e $2 \mathrm{~mL}$ de inóculo ruminal, mantidos em sala climatizada a $39 \pm 1^{\circ} \mathrm{C}$, em mesa de agitação orbital a 44 rpm e hermeticamente fechados. As leituras de pressão, em volts, foram medidas nos tempos 1, 2, 3, $4,5,6,9,12,18,24,30,36,48,60,72,84,96,120,144$, 168 e 192 horas após o início da incubação, em sistema semi-automático com transdutor de pressão acoplado a um voltímetro. A produção cumulativa de gases foi ajustada utilizando-se os modelos apresentados na Tabela 1.

Tabela 1. Descrição dos modelos estatísticos avaliados ${ }^{(1)}$.

\begin{tabular}{|c|c|c|}
\hline Modelos & Parâmetros & Equações uni ou bicompartimental \\
\hline Brody & 3 & $V(t)=V f\left[1-b e^{-k t}\right]+\varepsilon$ \\
\hline Von Bertalanffy & 3 & $V(t)=V f\left[1-b e^{-k t}\right]^{3}+\varepsilon$ \\
\hline Gompertz & 3 & 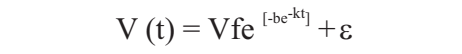 \\
\hline France & 4 & $V(t)=V f\left\{1-e^{[-b(t-\lambda)-c(\sqrt{t}-\sqrt{\lambda})]}\right\}+\varepsilon$ \\
\hline Logístico & 3 & $\mathrm{~V}(\mathrm{t})=\frac{\mathrm{Vf}}{1+\mathrm{e}^{[-(-\mathrm{b}+\mathrm{k} t)]}}+\varepsilon$ \\
\hline $\begin{array}{l}\text { Logístico } \\
\text { modificado }\end{array}$ & 3 & $\mathrm{~V}(\mathrm{t})=\frac{\mathrm{Vf}}{1+\mathrm{e}^{[2-4 \mathrm{k}(\mathrm{t}-\mathrm{x})]}}+\varepsilon$ \\
\hline $\begin{array}{l}\text { Logístico } \\
\text { bicompartimental }\end{array}$ & 1 & $\mathrm{~V}(\mathrm{t})=\frac{\mathrm{Vf}_{1}}{1+\mathrm{e}^{[2-4 \mathrm{k} \mid(t-\lambda)]}}+\frac{\mathrm{Vf}_{2}}{1+\mathrm{e}^{[2-4 k 2(t-\lambda)]}}+\varepsilon$ \\
\hline
\end{tabular}

${ }^{(1)} \mathrm{V}(\mathrm{t})$, volume acumulado $(\mathrm{mL})$ no tempo $\mathrm{t}$; Vf, volume total de gases produzido $(\mathrm{mL}) ; \mathrm{Vf}_{1}$, volume de gases produzido pela degradação da fração $\mathrm{A}+\mathrm{B}_{1}$ do Sistema de Cornell (CNF); $\mathrm{Vf}_{2}$, volume de gases produzido pela degradação da fração $\mathrm{B}_{2}$ do Sistema de Cornell (CF); k, taxa específica de produção de gases; $\mathrm{k}_{1}$, taxa específica de produção de gases pela degradação da fração $A+B_{1}(C N F) ; k_{2}$, taxa específica de produção de gases pela degradação da fração $\mathrm{B}_{2}(\mathrm{CF})$; $\mathrm{t}$, tempo de fermentação; $\lambda$, fase de latência; b e c, parâmetros de forma, sem interpretação biológica; e, exponencial; $\varepsilon$, erro experimental associado a cada observação, suposto $\sim \operatorname{NIID}\left(0, \sigma^{2}\right)$. 
A comparação entre modelos quanto ao ajustamento dos dados, haja vista que não há modelo verdadeiro, pressupõe hipótese nula de que todos os modelos são igualmente adequados para este fim, contra a hipótese alternativa de que um ou mais modelos são mais adequados que os outros.

Os critérios adotados para verificar a qualidade do ajuste foram coeficiente de determinação $\left(\mathrm{R}^{2}\right)$, quadrado médio do resíduo (QMR), análise gráfica das curvas observadas e estimadas, análise gráfica de resíduos, erro percentual médio (EPM) e eficiência relativa (ER). Adicionalmente, o número de iterações para atingir a convergência foi registrado, para posterior indicação do modelo, já que a complexidade do mesmo pode vir a cercear sua utilização na prática.

$\mathrm{OR}^{2}$ foi calculado de acordo com Souza (1998), como segue: $\mathrm{R}^{2}=1$ - (SQR/SQTotal ${ }_{c}$, em que $S Q R$ é a soma de quadrado do resíduo e $S Q T o t a l_{c}$ é a soma de quadrado total corrigida pela média.

O QMR utilizado foi:

QMR $=\tilde{\sigma}^{2}=\frac{\sum_{\mathrm{i}=1}^{\mathrm{n}}\left(\mathrm{y}_{\mathrm{i}}-\hat{\mathrm{y}}_{\mathrm{i}}\right)^{2}}{\mathrm{n}}=\frac{\mathrm{SQR}}{\mathrm{n}}$, sendo $\widetilde{\sigma}^{2} \mathrm{o}$ estimador de máxima verossimilhança da variância residual $\sigma^{2}$.

$\mathrm{Na}$ análise gráfica residual, os resíduos ordinários, calculados pela diferença entre os valores observados e estimados de acordo com o tempot, foram estudentizados conforme a versão padronizada do resíduo definida por aproximação linear assintótica, segundo Souza (1998): $\hat{\mu}_{\mathrm{i}}=\frac{\hat{\varepsilon}_{\mathrm{i}}}{\hat{\sigma} \sqrt{1-\hat{h}_{\mathrm{ii}}}}$, em que $\hat{\mu}_{\mathrm{i}}$ é o resíduo estudentizado para a observação $\mathrm{i}$; $\hat{\varepsilon}_{\mathrm{i}}$ é o resíduo ordinário da observação i; $\theta$ é o desvio-padrão residual

dado por $\hat{\sigma}=\sqrt{\frac{S Q R}{n-p}}=\sqrt{\frac{\sum_{i=1}^{n}\left(y_{i}-\hat{y}_{i}\right)^{2}}{n-p}}$, em que SQR é a soma de quadrados do resíduo; $y_{i}$ é o i-ésimo valor observado; $\hat{y}_{\mathrm{i}}$ é o i-ésimo valor estimado; n é o número de observações; $p$ é o número de parâmetros do modelo; $\hat{\mathrm{h}}_{\mathrm{ii}}$ - "leverage", representa a influência da i-ésima resposta sobre o i-ésimo valor ajustado. $\mathrm{O}$ modelo de regressão não-linear foi escrito na forma $y=f(\theta)+\varepsilon$, a matriz Jacobiana de $f(\theta)$ é $F(\theta)=\frac{\partial f(\theta)}{\partial \theta^{\prime}}$. Assim, $\hat{\mathrm{h}}_{\mathrm{ii}}$ é o i-ésimo elemento da matriz de projeção que é dada por $F(\hat{\theta})\left[F^{\prime}(\hat{\theta}) F(\hat{\theta})\right]^{-1} F^{\prime}(\hat{\theta})$.

O EPM foi dado por $E P M=\frac{1}{n} \sum_{i=1}^{n} E P_{i}$, em que $\mathrm{EP}_{\mathrm{i}}=100\left(\frac{\mathrm{y}_{\mathrm{i}}-\hat{\mathrm{y}}_{\mathrm{i}}}{\mathrm{y}_{\mathrm{i}}}\right)$ é o erro percentual para a i-ésima observação, designando se a função subestimou (+) ou superestimou (-) o valor observado.

A ER foi dada por $\operatorname{ER}(i / j)=\frac{\mathrm{QMR}_{j}}{\mathrm{QMR}_{\mathrm{i}}}, \operatorname{em~que} \operatorname{ER}(\mathrm{i} / \mathrm{j})$ é a eficiência relativa do modelo i em relação ao modelo j; $\mathrm{QMR}_{\mathrm{j}}=\widetilde{\sigma}_{\mathrm{j}}^{2}$ e $\mathrm{QMR}_{\mathrm{i}}=\widetilde{\sigma}_{\mathrm{i}}^{2}$ são os estimadores de máxima verossimilhança da variância residual $\sigma^{2}$, para os modelos j e i, respectivamente.

Os parâmetros dos modelos foram estimados pelo método iterativo de Marquardt inserido no procedimento NLIN do SAS (SAS Institute, 2005).

\section{Resultados e Discussão}

As curvas de produção cumulativa de gases observadas e ajustadas em silagens de girassol e milho podem ser vistas na Figura 1. Os modelos Brody e France foram menos efetivos no ajuste às curvas nos tempos iniciais de incubação ( 0 a 3 horas) em ambos substratos, pois subestimaram a produção de gases com valores negativos, sendo biologicamente impossível e atribuída ao parâmetro b, principal determinante desses valores iniciais. Além disso, esses modelos apresentaram crescimento exponencial enquanto as curvas de produção de gases, geralmente, apresentam forma sigmóide, distinguindo-se três fases: fase inicial com ausência ou lenta produção de gases, envolvendo hidratação, aderência e colonização microbiana (período de latência); fase exponencial com rápida produção de gases, representando a degradação enzimática; e fase assintótica com diminuição na taxa de produção de gases até alcançar o valor zero (Pell et al., 1997). Cone et al. (1997) caracterizaram diferentemente fase inicial, representando a fermentação da fração solúvel em detergente neutro; segunda fase, representando a fermentação da fração insolúvel em detergente neutro; e terceira fase, representando a renovação microbiana, detectável quando cessa a fermentação do substrato.

O modelo Brody pressupõe que a taxa específica de produção de gases é proporcional à quantidade de 
substrato e independente da massa microbiana (cinética de primeira ordem) e caracteriza-se por crescimento exponencial simples. Logo, este modelo pode ser mais hábil em descrever a produção de gases após o ponto de inflexão da fase inicial da curva ou em substratos em que o período de latência não é evidente ("lag time" discreto), considerando $t=0$ como ponto de inflexão e, dessa forma, podendo-se descrever toda a curva de produção de gases pós-incubação. Particularmente, quando as leituras da produção de gases não forem freqüentes na fase inicial (0 a 12 horas pós-incubação), o ponto de inflexão da curva não fica aparente e um modelo não sigmóide poderia descrever melhor os dados. Anteriormente, os modelos exponenciais comumente empregados em estudos in situ (Orskov \& McDonald, 1979; Mertens \& Loften, 1980; McDonald, 1981) foram utilizados na técnica in vitro de produção de gases, em que foi assumido que os substratos apresentavam características homogêneas e taxa de degradação constante ao longo do processo fermentativo (Fondevila \& Barrios, 2001). Os autores mencionaram ainda que o amplo conhecimento dessas equações entre os pesquisadores e a fácil interpretação fisiológica de seus parâmetros as tornam úteis na comparação de resultados, embora apresentem baixa acurácia.
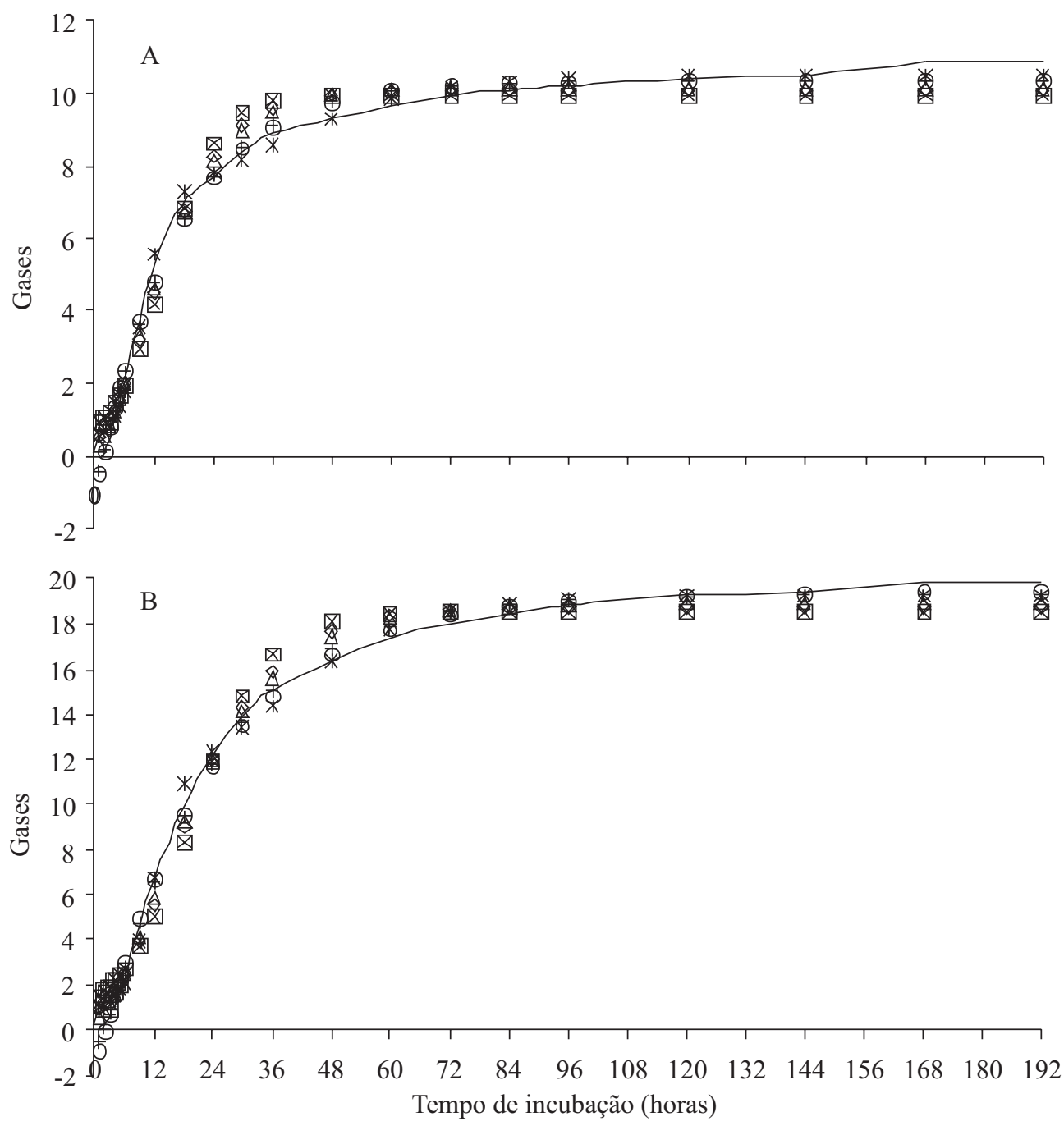

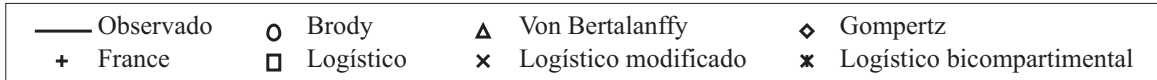

Figura 1. Curvas de produção cumulativa de gases (mL por $100 \mathrm{mg}$ de MS), ao longo do tempo de incubação, observadas e ajustadas pelos distintos modelos, em silagens de girassol (A) e milho (B). 
Segundo Dhanoa et al. (2000), o modelo France possui ampla flexibilidade em ajustar a forma sigmoidal ou não aos dados observados, o que não se comprovou neste trabalho, além de apresentar parâmetros com interpretação fisiológica questionável (Fondevila et al., 1999). No entanto, tal modelo, proveniente da generalização da equação de Mitscherlich, apresenta a vantagem de que a taxa específica de produção de gases pode variar ao longo do processo fermentativo (France et al., 1993).

Os modelos Von Bertalanffy, Gompertz, Logístico e Logístico modificado superestimaram o segundo ponto de inflexão da curva, ou seja, na transição entre o final da fase exponencial e início da fase assintótica, mais especificamente entre 24 e 60 horas pósincubação em silagens de girassol e entre 36 e 72 horas pós-incubação em silagens de milho. O modelo sigmóide Von Bertalanffy assume cinética de primeira ordem, e apresenta ponto de inflexão fixo em, aproximadamente, 0,30 do volume assintótico (Vf), o que diminui dessa forma a flexibilidade de ajuste à forma sigmoidal. O modelo Gompertz assume que a taxa específica é proporcional à massa microbiana, que, por sua vez, é decorrente da concentração de substrato digestível. Porém, a taxa fracional decai exponencialmente ao longo do tempo de incubação devido à inativação das bactérias por esgotamento do substrato (Schofield et al., 1994), com ponto de inflexão fixo em 0,37 de Vf. Os modelos logísticos pressupõem que a taxa específica é proporcional à quantidade de substrato e massa microbiana, todavia a taxa específica é fixa ao longo do tempo de incubação (Schofield et al., 1994) e ponto de inflexão limitado entre 0,20 e 0,40 de Vf, pela fixação de $b=1$ (Brown et al., 1976).

Todos os modelos subestimaram a fase assintótica após 144 horas de incubação em ambos os substratos, provavelmente, devido à refermentação por renovação microbiana nas curvas observadas após atingir o platô assintótico. Beuvink \& Kogut (1993) encontraram resultados semelhantes para o modelo Gompertz, que subestimou a assíntota e não se ajustou de forma adequada à fase exponencial da curva.

O modelo Logístico bicompartimental apresentou forma de curva adequada em todas as fases até 144 horas pós-incubação, com exceção de uma pequena tendência demonstrada nas 18 horas pósincubação em silagens de milho. Além disso, o modelo apresenta características do ponto de vista nutricional mais relevantes que os demais modelos, haja vista que esse possui artifícios matemáticos passíveis de calcular curvas de produção de gases pela degradação dos carboidratos totais (CT) e fração $\mathrm{B}_{2}$ do sistema de Cornell (CF). Procedendo-se à técnica de subtração, obtém-se uma terceira curva pela degradação das frações $\mathrm{A}+\mathrm{B}_{1}$ do sistema de Cornell (CNF), composta por açúcares solúveis, amido e pectina (Schofield \& Pell, 1995a). Assim, esse modelo divide a produção total de gases em dois compartimentos distinguidos pelas suas taxas de digestão (rápida e lenta). Conforme Doane et al. (1997), o compartimento duplo pode ocorrer pela fermentação de substratos heterogêneos, de duas populações microbianas distintas, ou pela combinação dos fatores.

Os autores relataram ainda que, quando a forrageira não é um substrato uniforme, o uso de modelos matemáticos mais complexos pode prever, de forma mais adequada, as mudanças na cinética de digestão das frações de carboidratos. De acordo com Schofield et al. (1994) e Groot et al. (1996), os modelos multicompartimentais apresentam maior qualidade de ajuste que os modelos baseados em cinética de primeira ordem. Adicionalmente, Fondevila \& Barrios (2001) mencionaram que os modelos multicompartimentais são mais adequados quando se utilizam um número muito grande de leituras, tal como ocorre nos sistemas automatizados, e que isso não ocorre quando o número de leituras é limitado, porém, de acordo com Pell et al. (2000) $n \geq 16$, leituras mais freqüentes na fase inicial são suficientes para proporcionar um ajuste adequado. No entanto, alguns autores (Dhanoa et al., 2000; France et al., 2000) recomendaram a utilização de modelos unicompartimentais devido a interpretação mecanicista, em preferência a puramente empírica dos modelos multicompartimentais.

O gráfico dos resíduos estudentizados em função do tempo t demonstra a qualidade do ajuste proporcionado por cada modelo. Caso o resíduo apresente-se distribuído aleatoriamente em relação à variável independente t é indicativo de que o ajuste foi adequado. Entretanto, se este se apresentar em blocos de valores positivos ou negativos é indicativo de autocorrelação residual positiva ou negativa, o que indica que o ajuste foi inadequado. Conforme a inspeção visual dos gráficos de dispersão dos resíduos (Figura 2), observa-se que os modelos Brody e France 
apresentaram dispersão idêntica em silagens de girassol e próxima em silagens de milho, com resíduo positivo e distinto aos padrões notados para os outros modelos nas primeiras horas de incubação. Os modelos Bertalanffy, Gompertz, Logístico e Logístico modificado seguiram a mesma tendência de dispersão em ambos os substratos. Observa-se maior dispersão residual até 60 horas pós-incubação em silagens de girassol e até 72 horas pós-incubação em silagens de milho, provavelmente, pela maior atuação microbiana durante esse período.

No entanto, os resíduos foram mais homogêneos entre 60 e 144 horas em silagens de girassol e entre 72 e
144 horas pós-incubação em silagens de milho, provavelmente, pela menor atividade microbiana. Além disso, destaca-se que os resíduos tenderam a apresentar valores fortemente positivos após 144 horas de incubação para todos os modelos ajustados em ambos os substratos, pois, normalmente, a assíntota já está estabelecida nesse período. A análise gráfica de dispersão residual não permitiu indicar um modelo que apresentasse menor dispersão em torno do eixo ao longo de todo o tempo de incubação.

Os dados referentes à análise quantitativa da qualidade de ajuste encontram-se na Tabela 2. Em relação ao $\mathrm{R}^{2}$, verifica-se que os modelos Brody, France e Logístico
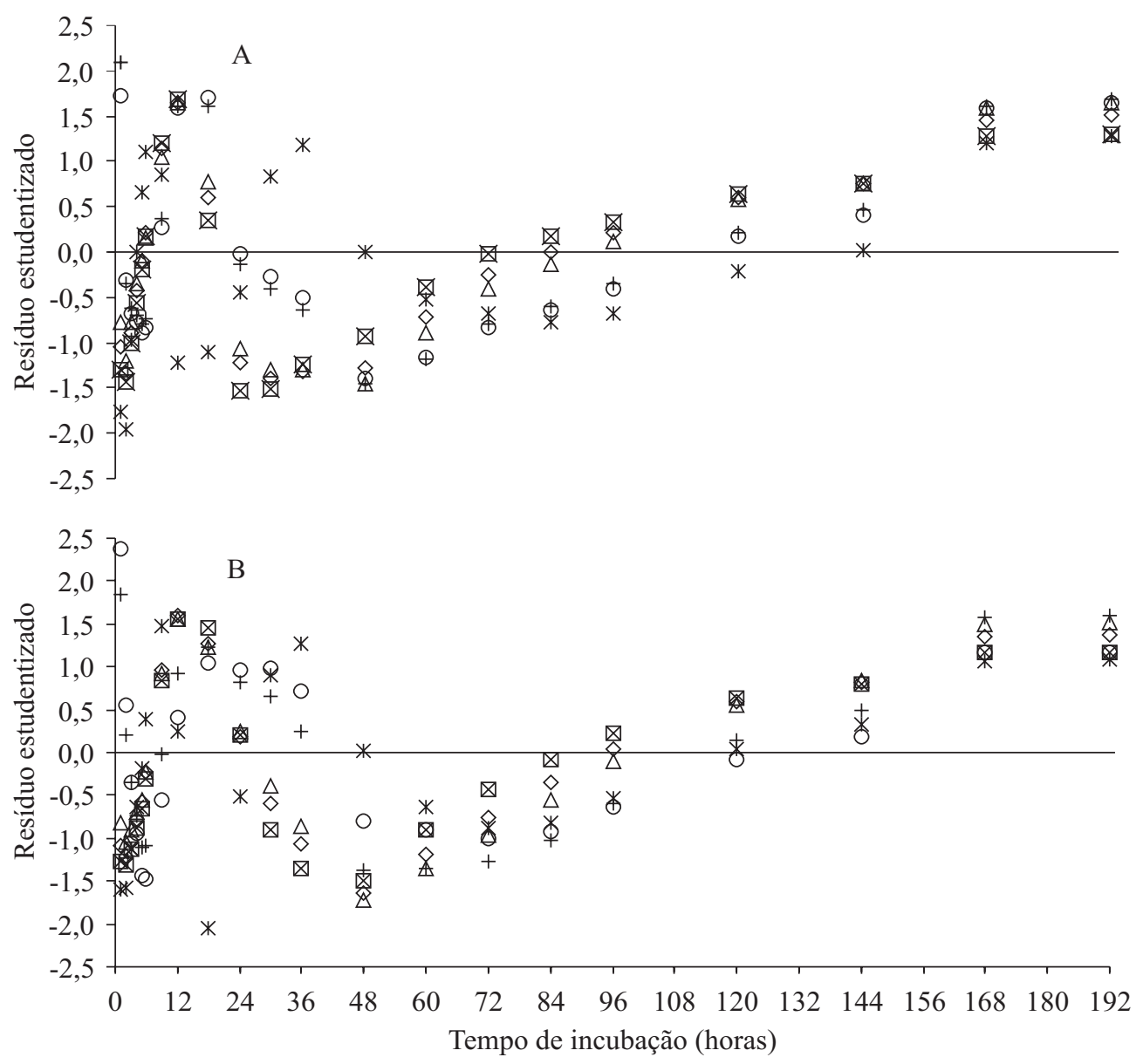

\begin{tabular}{|c|c|c|}
\hline $\begin{array}{l}\text { O Brody } \\
\text { + France } \\
\text { * Logístico bicompartimental }\end{array}$ & $\begin{array}{l}\triangle \text { Von Bertalanffy } \\
\square \text { Logístico }\end{array}$ & $\begin{array}{l}\diamond \text { Gompertz } \\
\times \text { Logístico modificado }\end{array}$ \\
\hline
\end{tabular}

Figura 2. Dispersão dos resíduos estudentizados ao longo do tempo de incubação para os distintos modelos ajustados em silagens de girassol (A) e milho (B). 
bicompartimental em ambos os substratos mais o modelo Bertalanffy em silagens de milho apresentaram $R^{2}$ superior a 0,99. Todavia, os modelos Brody e France subestimaram a produção inicial de gases com valores negativos, o que é biologicamente incoerente (Figura 1). Valores de $\mathrm{R}^{2}$ semelhantes aos encontrados neste estudo foram obtidos por Chen et al. (1999) no ajuste de modelo exponencial $\left(\mathrm{R}^{2}>0,99\right)$ e Schofield \& Pell (1995b) no ajuste do modelo logístico bicompartimental $\left(\mathrm{R}^{2}=0,9989 \pm 0,0005\right.$, $\mathrm{n}=72$ ). Apesar disso, as diferenças entre os modelos e substratos foram irrisórias e sem significado prático. Logo, as variações na produção de gases observadas foram bem representadas pelas variações estimadas nos modelos.

Este resultado permite inferir que o $\mathrm{R}^{2}$ analisado isoladamente não é um critério adequado para verificar a qualidade de ajustamento, pois não possibilita visualizar diferenças que podem ser facilmente detectadas na análise gráfica das curvas e dos resíduos estudentizados. Ratkowsky (1990) afirmou que mesmo havendo enorme discrepância entre os valores observados e estimados, os modelos não-lineares podem, às vezes, apresentar valores de $R^{2}$ extremamente elevados $\left(R^{2}=0,99\right)$. Do mesmo modo, o autor declarou que independentemente de haver ou não um termo constante (intercepto) no modelo, o $\mathrm{R}^{2}$ não tem nenhum significado óbvio em modelos de regressão não-linear e nunca precisa ser calculado. Assim, o $\mathrm{R}^{2}$ fornece apenas uma idéia da associação de $\hat{y}$ em relação a y, mas pouco alega sobre a aproximação biológica da curva, principalmente, em relação a sua forma.

$\mathrm{Na}$ avaliação do QMR, observa-se que o modelo Logístico bicompartimental apresentou menor variância residual em silagens de girassol, ao passo que o modelo France apresentou menor valor de QMR em silagens de milho (Tabela 2).
O EPM indica se os modelos superestimaram (valores positivos) ou subestimaram (valores negativos), em maior ou menor grau, os valores observados. Nota-se que o EPM foi negativo para todos os modelos em silagens de girassol, enquanto em silagens de milho apenas o modelo Brody apresentou valor positivo. Além disso, verifica-se que os modelos Brody e France apresentaram menores biases, ou seja, valores mais próximos da nulidade, em ambos os substratos. Todavia, ressalta-se que tais modelos apresentaram estimativas negativas nos tempos iniciais de incubação, sendo biologicamente impossível.

$\mathrm{Na}$ análise do número de iterações necessárias para que o critério de convergência fosse atendido, Dhanoa et al. (1995) mencionaram que o grande número de iterações pode ser indicativo de modelos inapropriados ou malcondicionados. Segundo Detmann et al. (2001), trabalhos com modelos de cinética de trânsito e digestão têm sugerido número de iterações menores que 20 como índice satisfatório. Neste trabalho, à exceção do modelo Logístico bicompartimental em silagens de milho, todos os demais modelos ajustados podem ser classificados como satisfatórios. Contudo, quanto maior o número de parâmetros do modelo, maior será o número de combinações possíveis, o que requer maior capacidade de processamento computacional e, conseqüentemente, maior número de iterações para atingir a convergência.

A ER é uma medida que reflete o grau relativo de precisão de um modelo em relação ao outro. Quando o valor de ER de um modelo sobre outro for maior que 1,0 $(E R>1)$ é indicativo de que esse modelo foi mais eficiente em relação ao outro. Pode se observar que o modelo Logístico bicompartimental apresentou ER maior que 1,0 em todas as comparações para silagens de girassol, enquanto o modelo France apresentou ER maior que 1,0 em todas as comparações para silagens de milho (Tabela 3), tendo sido os distintos modelos considerados mais eficientes nos respectivos substratos.

Tabela 2. Coeficientes de determinação $\left(\mathrm{R}^{2}\right)$, quadrado médio do resíduo (QMR), erro percentual médio (EPM) e número de iterações dos modelos ajustados para os diferentes substratos.

\begin{tabular}{|c|c|c|c|c|c|c|c|c|}
\hline \multirow[t]{2}{*}{ Modelos } & \multicolumn{4}{|c|}{ Silagens de girassol } & \multicolumn{4}{|c|}{ Silagens de milho } \\
\hline & $\mathrm{R}^{2}$ & QMR & EPM & Iterações & $\mathrm{R}^{2}$ & QMR & EPM & Iterações \\
\hline Brody & 0,9940 & 0,0964 & $-11,58$ & 4 & 0,9971 & 0,1678 & 1,29 & 4 \\
\hline Bertalanffy & 0,9885 & 0,1883 & $-44,32$ & 8 & 0,9932 & 0,4065 & $-28,94$ & 7 \\
\hline Gompertz & 0,9842 & 0,2621 & $-58,99$ & 10 & 0,9894 & 0,6460 & $-42,03$ & 6 \\
\hline France & 0,9940 & 0,0959 & $-12,23$ & 7 & 0,9975 & 0,1462 & $-1,57$ & 8 \\
\hline Logístico & 0,9725 & 0,4656 & $-81,28$ & 17 & 0,9788 & 1,3159 & $-66,42$ & 11 \\
\hline Logístico modificado & 0,9725 & 0,4656 & $-85,99$ & 14 & 0,9788 & 1,3159 & $-66,42$ & 9 \\
\hline Logístico bicompartimental & 0,9951 & 0,0865 & $-50,90$ & 18 & 0,9954 & 0,3111 & $-38,33$ & 25 \\
\hline
\end{tabular}


Tabela 3. Eficiência relativa (ER) entre as variâncias residuais para os modelos ajustados nos diferentes substratos.

\begin{tabular}{|c|c|c|c|c|c|c|c|}
\hline \multirow[t]{2}{*}{ Modelos $^{(1)}$} & \multicolumn{7}{|c|}{ Modelos $^{(2)}$} \\
\hline & Brody & Bertalanffy & Gompertz & France & Logístico & Log. modif. & Log. bicomp. \\
\hline & \multicolumn{7}{|c|}{ Silagens de girassol } \\
\hline Brody & - & 0,51 & 0,37 & 1,01 & 0,21 & 0,21 & 1,11 \\
\hline Bertalanffy & 1,95 & - & 0,72 & 1,96 & 0,40 & 0,40 & 2,18 \\
\hline Gompertz & 2,72 & 1,39 & - & 2,73 & 0,56 & 0,56 & 3,03 \\
\hline France & 0,99 & 0,51 & 0,37 & - & 0,21 & 0,21 & 1,11 \\
\hline Logístico & 4,83 & 2,47 & 1,78 & 4,85 & - & 1,00 & 5,38 \\
\hline Logístico modificado & 4,83 & 2,47 & 1,78 & 4,85 & 1,00 & - & 5,38 \\
\hline \multirow[t]{2}{*}{ Logístico bicompartimental } & 0,90 & 0,46 & 0,33 & 0,90 & 0,19 & 0,19 & - \\
\hline & \multicolumn{7}{|c|}{ Silagens de milho } \\
\hline Brody & - & 0,41 & 0,26 & 1,15 & 0,13 & 0,13 & 0,54 \\
\hline Bertalanffy & 2,42 & - & 0,63 & 2,78 & 0,31 & 0,31 & 1,31 \\
\hline Gompertz & 3,85 & 1,59 & - & 4,42 & 0,49 & 0,49 & 2,08 \\
\hline France & 0,87 & 0,36 & 0,23 & - & 0,11 & 0,11 & 0,47 \\
\hline Logístico & 7,84 & 3,24 & 2,04 & 9,00 & - & 1,00 & 4,23 \\
\hline Logístico modificado & 7,84 & 3,24 & 2,04 & 9,00 & 1,00 & - & 4,23 \\
\hline Logístico bicompartimental & 1,85 & 0,77 & 0,48 & 2,13 & 0,24 & 0,24 & - \\
\hline
\end{tabular}

${ }^{(1)}$ Modelo j para o cálculo de eficiência relativa. (2)Modelo i para o cálculo de eficiência relativa.

\section{Conclusão}

O modelo Logístico bicompartimental apresenta maior qualidade de ajuste às curvas de produção cumulativa de gases em silagens de girassol e milho.

\section{Referências}

BEUVINK, J.M.W.; KOGUT, J. Modeling gas production kinetics of grass silages incubated with buffered ruminal fluid. Journal of Animal Science, v.71, p.1041-1046, 1993.

BROWN, J.E.; FITZHUGH JUNIOR, H.A.; CARTWRIGHT, T.C.A. A comparison of nonlinear models for describing weight-age relationships in cattle. Journal of Animal Science, v.42, p.810-818, 1976.

CHEN, Y-K.; PELL, A.N.; CHASE, L.E.; SCHOFIELD, P. Rate and extent of digestion of the ethanol-soluble and neutral detergentinsoluble fractions of corn grain. Journal of Animal Science, v.77, p.3077-3083, 1999.

CONE, J.W.; VAN GELDER, A.H.; DRIEHUIS, F. Description of gas production profiles with a three-phasic model. Animal Feed Science and Technology, v.66, p.31-45, 1997.

CONE, J.W.; VAN GELDER, A.H.; VISSCHER, G.J.W.; OUDSHOORN, L. Influence of rumen fluid and substrate concentration on fermentation kinetics measured with a fully automated time related gas production apparatus. Animal Feed Science and Technology, v.61, p.113-128, 1996.

DAVIES, Z.S.; MASON, D.; BROOKS, A.E.; GRIFFITH, G.W.; MERRY, R.J.; THEODOROU, M.K. An automated system for measuring gas production from forages inoculated with rumen fluid and its use in determining the effect of enzymes on grass silage. Animal Feed Science and Technology, v.83, p.205-221, 2000.
DETMANN, E.; CECON, P.R.; PAULINO, M.F.; ZERVOUDAKIS, J.T;; VALADARES FILHO, S.C.; ARAÚJO, C.V. Estimação de parâmetros da cinética de trânsito de partículas em bovinos sob pastejo por diferentes seqüências amostrais. Revista Brasileira de Zootecnia, v.30, p.222-230, 2001.

DHANOA, M.S.; FRANCE, J.; SIDDONS, R.C.; LOPEZ, S.; BUCHANAN-SMITH, J.G. A non-linear compartmental model to describe forage degradation kinetics during incubation in polyester bags in the rumen. British Journal of Nutrition, v.73, p.3-15, 1995.

DHANOA, M.S.; LOPEZ, S.; DIJKSTRA, J.; DAVIES, D.R.; SANDERSON, R.; WILLIAMS, B.A.; SILESHI, Z.; FRANCE, J. Estimating the extent of degradation of ruminant feeds from a description of their gas production profiles observed in vitro: comparison of models. British Journal of Nutrition, v.83, p.131-142, 2000.

DOANE, P.H.; PELL, A.N.; SCHOFIELD, P. The effect of preservation method on the neutral detergent soluble fraction of forages. Journal of Animal Science, v.75, p.1140-1148, 1997.

FONDEVILA, M.; BARRIOS, A. The gas production technique and its application to the study of the nutritive value of forages. Cuban Journal of Agricultural Science, v.35, p.187-196, 2001.

FONDEVILA, M.; CUFRÉ, G.; NOGUEIRA, J.C.M.; GODIO, L.; ALCANTU, G. Digestion and microbial fermentation of Eragostris curvula supplemented with tallow. Animal Science, v.69, p.447-455, 1999.

FRANCE, J.; DHANOA, M.S.; THEODOROU, M.K.; LISTER, S.J.; DAVIES, D.R.; ISAC, D. A model to interpret gas accumulation profiles associated with in vitro degradation of ruminant feeds. Journal of Theoretical Biology, v.163, p.99-111, 1993.

FRANCE, J.; DIJKSTRA, J.; DHANOA, M.S.; LOPEZ, S.; BANNINK, A. Estimating the extent of degradation of ruminant feeds from a description of their gas production profiles observed in 
vitro: derivation of models and other mathematical considerations. British Journal of Nutrition, v.83, p.143-150, 2000.

GROOT, J.C.J.; CONE, J.W.; WILLIAMS, B.A.; DEBERSAQUES, F.M.A.; LANTINGA, E.A. Multiphasic analysis of gas production kinetics for in vitro fermentation of ruminant feeds. Animal Feed Science and Technology, v.64, p.77-89, 1996.

MAURÍCIO, R.M.; MOULD, F.L.; DHANOA, M.S.; OWEN, E.; CHANNA, K.S.; THEODOROU, M.K. A semi-automated in vitro gas production technique for ruminant feedstuff evaluation. Animal Feed Science and Technology, v.79, p.321-330, 1999.

McDONALD, I. A revised model for the estimation of protein degradability in the rumen. Journal of Agricultural Science, v.96, p.251-252, 1981.

McDOUGALL, E.I. Studies on ruminant saliva. 1. The composition and output of sheep's saliva. Biochemical Journal, v.43, p.99-109, 1948.

MENKE, K.H.; RAAB, L.; SALEWSKI, A.; STEINGASS, H.; FRITZ, D.; SCHNEIDER, W. The estimation of the digestibility and metabolizable energy content of ruminant feedingstuffs from the gas production when they incubated with liquor in vitro. Journal of Agricultural Science, v.93, p.217-222, 1979.

MENKE, K.H.; STEINGASS, H. Estimation of the energetic feed value obtained from chemical analysis and in vitro gas production using rumen fluid. Animal Research and Development, v.28, p.755, 1988.

MERTENS, D.R.; LOFTEN, J.R. The effect of starch on forage fiber digestion kinetics in vitro. Journal of Dairy Science, v.63, p.1437-1446, 1980.

ORSKOV, E.R.; McDONALD, I. The estimation of protein degradability in the rumen from incubation measurements weighted according to rate of passage. Journal of Agricultural Science, v.92, p.499-503, 1979.

PELL, A.N.; DOANE, P.H.; SCHOFIELD, P. In vitro digestibility and gas production. In: REUNIÃO ANUAL DA SOCIEDADE
BRASILEIRA DE ZOOTECNIA, 34., 1997, Juiz de Fora. Anais. Juiz de Fora: SBZ, 1997. p.109-132.

PELL, A.N.; MOLINA, D.O.; SCHOFIELD, P. Measurement of gas production in vitro. In: DEAVILLE, E.; WILLIAMS, B.A.; CONE, J.; TAMMINGA, S.; GIVENS, D.I. (Ed.). Gas production: fermentation kinetics for feed evaluation and to assess microbial activity. Wageningen: BSAS, 2000. p.1-12.

PELL, A.N.; SCHOFIELD, P. Computerized monitoring of gas production to measure forage digestion in vitro. Journal of Dairy Science, v.76, p.1063-1073, 1993.

RATKOWSKY, D.A. Handbook of nonlinear regression models. New York: Marcel Dekker Inc., 1990. 241p.

SAS INSTITUTE. SAS system for windows: versão 9.0. Cary: SAS Institute, 2005.

SCHOFIELD, P.; PELL, A.N. Measurement and kinetic analysis of the neutral detergent soluble carbohydrate fraction of legumes and grasses. Journal of Animal Science, v.73, p.3455-3463, 1995a.

SHOFIELD, P.; PELL, A.N. Validity of using accumulated gas pressure readings to measure forage digestion in vitro: a comparison involving three forages. Journal of Dairy Science, v.78, p.22302238, 1995 b.

SCHOFIELD, P.; PITT, R.E.; PELL, A.N. Kinetics of fiber digestion from in vitro gas production. Journal of Animal Science, v.72, p.2980-2991, 1994.

SOUZA, G.S. Introdução aos modelos de regressão linear e nãolinear. Brasília: Embrapa-SPI, 1998. 505p.

THEODOROU, M.K.; WILLIAMS, B.A.; DHANOA, M.S.; McALLAN, A.B.; FRANCE, J.A simple gas production method using a pressure transducer to determine the fermentation kinetics of ruminant feeds. Animal Feed Science and Technology, v.48, p.185197, 1994.

THORNLEY, J.H.M.; FRANCE, J. Mathematical models in agriculture: quantitative methods for the plant, animal and ecological sciences. $2^{\text {nd }}$ ed. Wallingford: CABI, 2007. 906p.

Recebido em 2 de outubro de 2007 e aprovado em 21 de janeiro de 2008 